\title{
HUBUNGAN KARAKTERISTIK DENGAN PHBS DI SMA NEGERI 1 PANCUR BATU
}

\author{
Pomarida Simbolon \\ Staf Pengajar STIKes Santa Elisabeth Medan
}

\begin{abstract}
ABSTRAK
Latar Belakang : Sekolah sebagai salah satu pusat pendidikan bagi anak-anak bangsa, hingga kini belum bisa melaksanakan anjuran untuk bisa berperilaku hidup bersih dan sehat. Bila PHBS tidak dilakukan dengan baik maka akan menimbulkan dampak yang tidak diinginkan yaitu munculnya berbagai penyakit serta status kesehatan yang tidak baik. Hal ini ditemukan pada SMA Negeri 1 Pancur Batu Kabupaten Deli Serdang.

Tujuan : Tujuan penelitian untuk mengetahui hubungan karakteristik dengan PHBS di SMA negeri 1 Pancur Batu.

Metode : Jenis penelitian cross sectional yang dilaksanakan di SMA Negeri 1 Pancur Batu. Sampel dalam penelitian berjumlah 88 orang dengan teknik simple random sampling. Pengumpulan data dengan menggunakan kuesioner. Data dianalisis dengan menggunakan uji chi square.

Hasil : Hasil penelitian diperoleh ada hubungan jenis kelamin ( $\mathrm{p}=0,007$, tingkat kelas ( $\mathrm{p}$ $=0,001)$ dengan PHBS.

Kesimpulan : Disarankan kepada pihak Sekolah SMA Negeri 1 Pancur Batu agar bekerjasama dengan Puskesmas Pancur Batu untuk membuat jadwal tentang pemberian pendidikan kesehatan sehingga pengetahuan anak sekolah lebih update tentang PHBS.
\end{abstract}

Kata kunci: Jenis Kelamin, Tingkat Kelas, PHBS

\section{ABSTRACT}

Bacground: Schools as one of the centers of education for the children of the nation, up to now have not been able to carry out recommendations to be able to behave clean and healthy. If PHBS is not done well, it will cause undesirable effects, namely the emergence of various diseases and poor health status. This was found in 1 Pancur Batu Public High School in Deli Serdang District.

Goals : The purpose of the study was to determine the relationship of characteristics with PHBS in-state high schools 1 Pancur Batu.

Methods: This type of research is cross-sectional conducted at 1 Pancur Batu Public High School. The sample in the study amounted to 88 people with a simple random sampling technique. Data collection using a questionnaire. Data were analyzed using the chi-square test.

Results: The results showed that there was a sex relationship $(p=0.007$, class level $(p=0.001)$ with PHBS.

Conclusion: It was suggested that the 1 Pancur Batu Public High School be advised to collaborate with Pancur Batu Health Center to create a schedule for providing health education so that knowledge of school children more updates about PHBS.

\section{Keywords: Gender, Grade Level, PHBS}

\section{PENDAHULUAN}

Menciptakan suasana yang nyaman bagi sekolah sebagai tempat pembelajaran yang kondusif merupakan rasa tanggung jawab bagi warga sekolah dalam upaya meningkatkan derajat kesehatan 
masyarakat. Derajat kesehatan masyarakat akan semakin baik melalui prilaku masyarakat. Masyarakat pada umumnya mempunyai harapan dalam kehidupan sehari-hari. Harapan utama yaitu agar manusia hidup aman, tentram, rukun, bersih, dan makmur. Semua harapan itu bisa tercapai karena masyarakat itu sendiri yang berusaha untuk mencapai harapan tersebut.

Salah satu lokasi yang dapat menerapkan derajat kesehatan masyarakat tersebut yaitu melalui pengelolaan sekolah. Pengelolaan sekolah di satu sisi dapat menampilkan kondisi yang kontradiktif jika ditinjau dari sudut pelestarian lingkungan. Hal ini terutama ditandai dengan perilaku guru dan murid sekolah yang tidak berwawasan lingkungan seperti pemakaian air bersih berlebihan, membuang sampah di sembarang tempat, lingkungan sekolah yang gersang tanpa tumbuhan dan sebagainya. Disisi lain sarana dan prasarana lingkungan binaan yang diharapkan dapat mendukung fasilitas sekolah terkadang direncanakan dengan mengabaikan prinsip pelestarian lingkungan hidup misalnya pembangunan lapangan sekolah yang masih minim sehingga mengurangi luasan area resapan air yang dapat menyebabkan polusi lingkungan. Polusi lingkungan terjadi pada sekolah terutama diakibatkan oleh perilaku kebersihan lingkungan yang negatif seperti berbagai bentuk pengotoran atau pembuangan sampah secara sembarangan.

Pengelolaan sekolah pada kondisi dan situasi tertentu ternyata disikapi oleh guru dan murid dengan budaya yang "kurang sadar lingkungan" akibat tidak disertakannya mereka berpartisipasi aktif terhadap pengelolaan sekolah, sikap cenderung masa-bodoh apatis dan tidak mendukung terhadap keberadaan sekolah di daerahnya. Hal ini secara psikologis menimbulkan perasaan kurang nyaman dan aman ketika siswa melaksanakan kegiatan belajar mengajar (KBM).

Teori Blum menyatakan bahwa derajat kesehatan dipengaruhi 4 (empat) macam faktor yaitu lingkungan, perilaku, pelayanan kesehatan, dan hereditas. Faktor lingkungan dan perilaku merupakan faktor terbesar yang berpengaruh terhadap tinggi rendahnya derajat kesehatan. Oleh karena itu, lingkungan sehat dan perilaku sehat perlu diupayakan dengan sungguh-sungguh. Pada tatanan sekolah perilaku tersebut tergambar dalam karakteristik siswa yang dapat merubah derajat kesehatan masyarakat melalui pelaksanaan PHBS.

PHBS merupakan salah satu program prioritas pemerintah melalui puskesmas dan menjadi sarana luaran dalam penyelenggaraan pembangunan kesehatan, seperti yang disebutkan pada Rencana strategi (Renstra) kementerian kesehatan tahun 2010-2014. Sasaran tidak hanya terbatas tentang hygiene, namun lebih komprehensif dan luas, mencakup perubahan fisik, lingkungan biologi dan lingkungan sosial-budaya masyarakat sehingga tercipta lingkungan yang berwawasan kesehatan dan perubahan hidup bersih dan sehat.

Dalam pelaksanaan PHBS setiap individu harus sadar, mau dan mampu mempraktekkannya. Cakupan dalam PHBS antara lain mencuci tangan menggunakan sabun, mengkonsumsi makanan dan minuman sehat, menggunakan jamban sehat, membuang sampah di tempat sampah, tidak merokok, tidak mengkonsumsi narkoba, alkohol, psikotropika dan zat aditif lainnya (NAPZA), tidak meludah sembarang tempat, memberantas jentik-jentik nyamuk.

Salah satu indikator untuk dapat mewujudkan PHBS yaitu adanya karakteristik dari masyarakat untuk melaksanakan PHBS dan masalah PHBS merupakan hal utama disetiap daerah yang menjadi harapan besar suatu masyarakat dalam bidang kebersihan lingkungan yang selalu dijadikan permasalahan yang sulit diselesaikan. Kebersihan lingkungan selalu hanya menjadi sebuah harapan yang besar bagi setiap masyarakatnya, namun tidak diiringi dengan usaha untuk mewujudkannya. Perwujudan tersebut dalam pelaksanaan di lingkungan sekolah 
dipengaruhi oleh tingkat pendidikan dan jenis kelamin.

Sekolah sebagai salah satu pusat pendidikan bagi anak-anak bangsa, hingga kini belum bisa melaksanakan anjuran untuk bisa hidup bersih dan sehat, walaupun diketahui itu indah. Kenyataannya, banyak sekolah yang masih belum bersih dan indah, bahkan sangat gersang karena tidak ditanami dengan pohon-pohon yang menyejukkan. Banyak sekolah yang masih dikotori dengan sampah. Ada kamar mandi dan WC tersedia, namun kondisinya sangat kotor atau jorok sehingga sangat mengganggu lingkungan sekitar sekolah.

Seharusnya, sekolah sebagai sebuah lembaga pendidikan dan tempat anak bisa belajar harus dapat menerapkan tentang tata cara mengelola sampah yang benar dan bermanfaat. Namun banyak sekolah yang hingga kini tidak mengelola sampah dengan benar. Anak-anak dalam keseharian masih membuang sampah di selokan dan di sungai-sungai. Walau di sekolah sering diajarkan bahwa membuang sampah di sungai dan selokan bisa menyebabkan banjir dan menjadi sumber penyakit yang dapat merugikan diri sendiri dan orang lain.

Pengelolaan sampah RT di Indonesia umumnya dilakukan dengan cara dibakar $(50,1 \%)$ dan hanya 24,9 persen yang diangkut oleh petugas. Cara lainnya dengan cara ditimbun dalam tanah, dibuat kompos, dibuang ke kali/ parit/ laut dan dibuang sembarangan. Lima provinsi dengan proporsi RT yang mengelola sampah dengan cara dibakar tertinggi adalah Gorontalo (79,5\%), Aceh (70,6\%), Lampung (69,9\%), Riau (66,4\%), dan Kalimantan Barat (64,3\%) (Riskesdas, 2013)

Anak usia sekolah merupakan masa keemasan untuk menanamkan nilai-nilai PHBS dan mempromosikannya baik dalam sekolah, keluarga maupun masyarakat. Saat ini di Indonesia terdapat lebih dari 12409 sekolah, berdasarkan jumlah tersebut sekolah merupakan tempat yang strategis dalam kehidupan anak, maka sekolah dapat difungsikan secara tepat sebagai salah satu institusi yang dapat membantu dan berperan dalam upaya optimalisasi tumbuh kembang anak sekolah dengan upaya promotif dan preventif (BPS, 2015).

Masalah kesehatan anak sekolah meliputi masalah yang berkaitan dengan Perilaku Hidup Bersih dan Sehat (PHBS), seperti kecacingan, diare, karies gigi/ gigi berlubang, masalah yang berkaitan dengan faktor berisiko (penyalahgunaan narkoba, seks bebas, penyakit infeksi menular seksual termasuk HIV/ AIDS, Infeksi Saluran Reproduksi), masalah gizi (gizi kurang, gizi buruk, gizi lebih, anemia) serta gangguan kesehatan yang berkaitan dengan sanitasi dasar (air bersih, jamban/ WC, dan pembuangan air limbah) yang kurang memenuhi syarat kesehatan seperti tipus, kolera, disentri. Hal tersebut yang rentan pada pendidikan Sekolah dan adanya ancaman sakit terhadap anak sekolah masih tinggi dengan adanya penyakit endemis dan kekurangan gizi (Notoatmodjo, 2012).

Penyakit yang diderita oleh anak sekolah dasar terkait perilaku seperti cacingan 40-60\%, anemia $23,2 \%$, karies dan periodontal $74,4 \%$ (Depkes, 2005). Persentase orang merokok tertinggi $(19,7 \%)$ berada pada kelompok usia remaja (10-19 tahun), sebagian besar (59\%) penduduk yang berusia 10 tahun keatas kurang melakukan aktifitas fisik. Kondisi PHBS di Sumatera Utara dapat dilihat dari persentase rumah tangga ber PHBS 54,30\%, masalah keamanan makanan yang dijual di sekitar sekolah yang belum menerapkan prinsipprinsip Hygiene (Riskesdas, 2013). Bila PHBS tidak dilakukan dengan baik maka akan menimbulkan dampak yang tidak diinginkan yaitu munculnya berbagai penyakit dan hal ini juga ditemukan pada SMA Negeri 1 Pancur Batu Kabupaten Deli Serdang,

\section{METODE PENELITIAN}

Penelitian ini bersifat deskriptif analitik yaitu menganalisis hubungan antara beberapa variabel yaitu jenis kelamin dan 
suku dengan Perilaku Hidup Bersih dan Sehat (PHBS) pada Sekolah Menengah Atas di wilayah Kerja Puskesmas Pancur Batu dengan melihat kenyataan yang sebenarnya terjadi di lapangan. Data dalam penelitian akan menggunakan data primer dan sekunder.

Populasi dalam penelitian ini adalah seluruh siswa SMA Negeri 1 kelas 1 dan kelas 2 yang ada di wilayah kerja Puskesmas Pancur Batu Kabupaten Deli Serdang sebanyak 88 orang. Dalam penelitian ini pengambilan sampel ditentukan dengan menggunakan cara acak sederhana (Simple Random Sampling) yaitu dengan undi (Sugiyono, 2013b). Pengumpulan data dilakukan dengan menggunakan observasi dan kuesioner. Analisis data pada Penelitian Dosen Pemula ini menggunakan analisis bivariat dengan menggunakan uji statistik chi square. Penafsiran dan kesimpulan dilakukan setelah terkumpulnya hasil analisis data untuk selanjutnya dibuat kesimpulan berdasarkan hasil analisis tersebut (Sugiyono, 2013a).

\section{HASIL PENELITIAN}

\section{Karakteristik Responden}

Hasil penelitian menunjukkan bahwa berdasarkan jenis kelamin perempuan 56 orang $(63,6 \%)$ dan laki-laki 32 orang $(36.4 \%)$. Berdasarkan tingkat kelas terbanyak XI 54,5\%. Disteribusi responden berdasarkan karakteristik dapat dilihat pada tabel 1 .

Tabel 1. Distribusi Frekuensi dan Persentase Karakteristik Responden SMA Negeri 1 Pancur Batu Tahun 2018

\begin{tabular}{lcc}
\hline Karakteristik & f & $\mathbf{\%}$ \\
\hline Jenis kelamin & & \\
Laki-laki & 32 & 36,4 \\
Perempuan & 56 & 63,6 \\
\hline Total & $\mathbf{8 8}$ & $\mathbf{1 0 0 , 0}$ \\
\hline Tingkat Kelas & & \\
X & 40 & 45,5 \\
XI & 48 & 54,5 \\
\hline Total & $\mathbf{8 8}$ & $\mathbf{1 0 0 , 0}$ \\
\hline
\end{tabular}

\section{PHBS}

Hasil penelitian menunjukkan bahwa sebagian besar siswa mempunyai Perilaku Hidup Bersih dan Sehat yang baik sebanyak 57 orang $(64,8 \%)$. Distribusi responden berdasarkan PHBS dapat dilihat pada tabel 2.

Tabel 2. Distribusi Responden Berdasarkan Variabel Perilaku Hidup Bersih dan Sehat di SMA Negeri 1 Pancur Batu Tahun 2018

\begin{tabular}{lcc}
\hline PHBS & $\mathbf{f}$ & \% \\
\hline Baik & 57 & 64,8 \\
Kurang & 31 & 35,2 \\
\hline \multicolumn{1}{c}{ Total } & $\mathbf{8 8}$ & $\mathbf{1 0 0 , 0}$ \\
\hline
\end{tabular}

3. Hubungan Karakteristik dengan Perilaku Hidup Bersih dan Sehat

Hubungan jenis kelamin dengan

Perilaku Hidup Bersih dan Sehat berdasarkan hasil analisis uji chi square diperoleh bahwa ada sebanyak 27 dari 32 $(84,4 \%)$ yang berjenis kelamin perempuan dengan Perilaku Hidup Bersih dan Sehat baik dan ada sebanyak 30 dari $56(53,6 \%)$ yang berjenis kelamin perempuan dengan perilaku Hidup Bersih dan Sehat yang baik.

Hasil uji statistik diperoleh $(\mathrm{OR}=$ 4,680; CI 95\% 1,575 hingga 13,909; $\mathrm{p}=0,007)$ maka dapat disimpulkan bahwa ada hubungan yang bermakna antara jenis kelamin dengan Perilaku Hidup Bersih dan Sehat di SMA Negeri 1 Pancur Batu Tahun 2018. Odd ratio jenis kelamin dengan Perilaku Hidup Bersih dan Sehat adalah 4,680. Hal ini menunjukkan bahwa siswa laki-laki memiliki peluang 4.680 kali untuk berperilaku Hidup Bersih dan Sehat dibandingkan dengan siswa wanita.

Hubungan tingkat kelas dengan Perilaku Hidup Bersih dan Sehat berdasarkan hasil analisis uji chi square diperoleh bahwa ada sebanyak 39 dari 48 $(81,3 \%)$ pada tingkat kelas $\mathrm{X}$ dengan Perilaku Hidup Bersih dan Sehat baik dan ada sebanyak 22 dari $40(55,0 \%)$ pada tingkat kelas XI dengan perilaku Hidup Bersih dan Sehat yang kurang. 
Hasil uji statistik diperoleh $(\mathrm{OR}=$ 5,296; CI 95\% 2,037 hingga 13,773; $\mathrm{p}=0,001)$ maka dapat disimpulkan bahwa ada hubungan yang bermakna antara tingkat kelas dengan Perilaku Hidup Bersih dan Sehat di SMA Negeri 1 Pancur Batu Tahun 2018. Odd ratio tingkat kelas dengan
Perilaku Hidup Bersih dan Sehat adalah 5,296 . Hal ini menunjukkan bahwa tingkat kelas XI memiliki peluang 5,296 kali untuk berperilaku Hidup Bersih dan Sehat dibandingkan dengan kelas X. Hasil uji chi square dapat dilihat pada tabel 3 .

Tabel 3. Distribusi Frekuensi Hubungan Karakteristik dengan Perilaku Hidup Bersih dan Sehat di SMA Negeri 1 Pancur Batu Tahun 2018

\begin{tabular}{|c|c|c|c|c|c|c|c|c|c|c|}
\hline \multirow{3}{*}{ Karakteristik } & \multicolumn{6}{|c|}{ Perilaku Hidup Bersih dan Sehat } & \multirow{3}{*}{ p.value } & \multirow{3}{*}{ OR } & \multirow{2}{*}{\multicolumn{2}{|c|}{$95 \% \mathrm{CI}$}} \\
\hline & \multicolumn{2}{|c|}{ Baik } & \multicolumn{2}{|c|}{ Kurang } & \multicolumn{2}{|c|}{ Total } & & & & \\
\hline & n & $\%$ & n & $\%$ & $\mathbf{N}$ & $\%$ & & & Lower & Upper \\
\hline Jenis kelamin & & & & & & & & & & \\
\hline Perempuan & 27 & 84,4 & 5 & 15,6 & 32 & 100,0 & 0,007 & 4,680 & 1,575 & 13,909 \\
\hline Laki-laki & 30 & 53,6 & 26 & 46,4 & 56 & & & & & \\
\hline Tingkat Kelas & & & & & & & & & & \\
\hline $\mathrm{X}$ & 18 & 45,0 & 22 & 55,0 & 40 & 100,0 & 0,001 & 5,296 & 2,037 & 13,773 \\
\hline XI & 39 & 82,3 & 9 & 18,8 & 48 & & & & & \\
\hline
\end{tabular}

\section{PEMBAHASAN}

\section{Hubungan Jenis kelamin dengan} Perilaku Hidup Bersih dan Sehat

Jenis kelamin merupakan salah satu bagian dari karakteristik. Penerapan perilaku hidup bersih dan sehat antara jenis kelamin laki-laki maupun perempuan mempunyai hak yang sama karena kesehatan diperlukan tidak hanya perempuan atau laki-laki saja. Hasil penelitian menunjukkan ada hubungan jenis kelamin dengan dengan PHBS hal ini sejalan dengan Teori Green bahwa faktor demografi (jenis kelamin) mempengaruhi perilaku kesehatan.

Penelitian ini tidak sejalan dengan penelitian Sari, Widjanarko, Kusumawati (2016), Nurmalita (2016) bahwa laki-laki dan perempuan mempunyai andil yang sama dalam upaya meningkatkan kesehatannya dapat diterapkan dalam kehidupan sehari-hari melalui berperilaku hidup bersih dan sehat. Salah satu indikator dalam PHBS yaitu membuang sampah. Apabila sudah membuang sampah dengan baik makan PHBS dari sekolah tersebut sudah baik juga.

Hasil penelitian ini sejalan dengan (Bachtiar, 2015) indikator pelaksanaan program Gerakan Pungut Sampah (GPS) terlaksana dengan baik sehingga dapat meningkatkan karakter peduli lingkungan terlaksana dengan baik sesuai dengan surat edaran yang dikeluarkan oleh Pemerintah Kota Bandung nomor 660/SE. 098_BPLH tentang Gerakan Pungut Sampah.

Program Gerakan Pungut Sampah (GPS) bertujuan untuk menciptakan budaya di lingkungan masyarakat agar lebih peduli terhadap lingkungan yang bersih dari sampah. Seperti yang dikemukakan oleh Badan Pengelolaan Lingkungan Hidup Kota Bandung bahwa tujuan dari program Gerakan Pungut Sampah (GPS) adalah membentuk perilaku masyarakat agar menjaga lingkungan bebas sampah dan menempatkan sampah sesuai dengan kategorinya pada tempat yang disediakan.

Sesuai dengan pernyataan di atas, program Gerakan Pungut Sampah (GPS) membantu meningkatkan karakter siswa dalam kepedulian lingkungan. Hal ini merupakan peningkatan karakter baik pada diri siswa berdasarkan jenis kelamin. Seperti yang diungkapkan oleh Lickona (2012) bahwa karakter yang baik terdiri dari mengetahui hal yang baik, menginginkan hal yang baik, dan melakukan hal yang baik. Kebiasaan dalam cara berfikir, 
kebiasaan dalam hati, dan kebiasaan dalam tindakan serta didukung oleh adanya fasilitas kesehatan di lingkungan seperti di sekolah.

Menurut Notoadmodjo (2007) yaitu keberhasilan dari sekolah menjadi lebih baik karena adanya tanggung jawab guru dimana sekolah merupakan salah satu perpanjangan tangan tangan pendidikan kesehatan. Guru Di SMA Negeri 1 Pancur Batu telah menerapkan metode pembelajaran yang digunakan untuk membuat siswa aktif dalam pembelajaran. Mata pelajaran yang sering diinternalisasikan dalam operasi pungut sampah dan PHBS yaitu biologi, sosiologi, seni budaya dan keterampilan (SBK) serta agama.

Hal lain yang mendukung PHBS telah baik yaitu adanya kegiatan ekstrakurikuler seperti PA (Pendalaman Alkitab) setiap hari Jumat dan sholat bagi yang beragama muslim yang mengajarkan tentang sikap dan tingkah laku yang baik dan peka terhadap lingkungan dan dalam kegiatan ini yang berperan dalam memberi ilmu pengetahuan yaitu guru dan pemuka agama sehingga responden bertindak dan berperilaku dengan baik.

Perilaku seseorang terbentuk dipengaruhi oleh pengetahuan, sikap serta tindakan. Terdapat tiga perilaku kesehatan yaitu, perilaku sehat, perilaku sakit dan perilaku orang sakit. Perilaku sehat merupakan suatu kegiatan yang dilakukan seseorang untuk meningkatkan serta mempertahankan kesehatannya sehingga seseorang tersebut tidak sampai terserang penyakit (Glanz, dkk, 2008). Apabila seseorang dapat melakukan perilaku sehat ini maka PHBS dapat diterapkan dengan baik sehingga seseorang dapat meningkatkan kesehatannya.

\section{Hubungan Tingkat Kelas dengan Perilaku Hidup Bersih dan Sehat}

Hasil penelitian di SMA Negeri 1

Pancur Batu menunjukkan ada hubungan tingkat kelas dengan PHBS. Hasil penelitian ini didukung oleh penelitian
Nurmalita (2016) yaitu adanya hubungan antara tingkat kelas dengan perilaku penggunaan fasilitas MCK dikarenakan semakin tinggi tingkat kelas/ tingkat pendidikan seorang siswa, akan semakin mudah menerima informasi sehingga bertambah pengetahuan yang murid tersebut dalam berperilaku sehat. Dengan semakin bertambahnya pengetahuan siswasiswi tersebut, maka akan berdampak pada perilaku yang diterapkan murid dalam kehidupan sehari-hari. dalam penelitian ini responden yang ada di SMA Pancurabatu paling banyak kelas XI daripada X sehingga tingkat pendidikan yang lebih tinggi sudah lebih dahulu memperoleh informasi.

PHBS di SMA Negeri 1 pancur Batu telah baik disebabkan oleh tingkat pendidikan yang sudah mengetahui informasi tentang PHBS, usia responden dan adanya kesadaran untuk melakukan PBHS dengan baik. Hal ini sejalan dengan pendapat Notoadmodjo (2014) yang menyatakan bahwa faktor PHBS sudah baik disebabkan perilaku dari pada seorang individu. Menurut Green membedakan adanya dua faktor yang menjadi penyebab masalah kesehatan, yaitu behavioral factors (faktor perilaku) dan non-behavioral factors (faktor non-perilaku). Faktor perilaku sendiri ditentukan oleh 3 faktor utama antara lain faktor-faktor predisposisi (predisposing factors) merupakan faktorfaktor yang mempermudah terjadinya perilaku seseorang, antara lain pengetahuan, sikap, keyakinan, kepercayaan, nilai-nilai, tradisi, dan faktor demografi (usia, jenis kelamin, status sosial ekonomi), faktorfaktor pemungkin (enabling factors) merupakan faktor-faktor yang memungkinkan atau yang memfasilitasi perilaku atau tindakan, diantaranya sarana dan prasarana (fasilitas), biaya, jarak, dan ketersediaan transportasi, faktor-faktor penguat (reinforcing factors) merupakan faktor-faktor yang mendorong atau memperkuat terjadinya perilaku seperti tokoh masyarakat, keluarga, teman, guru, dan petugas kesehatan. 
Tingkat pendidikan responden pada penelitian ini yaitu SMA dan usia responden sudah memasuki remaja, berdasarkan faktor tersebut sebagian besar responden sudah ada kesadaran dari diri sendiri tanpa harus diperintahkan lagi oleh guru maupun orang tua. Berdasarkan teori HBM manfaat yang dirasakan lebih menentukan tindakan yang akan diambil seseorang (Glanz dkk, 2008).

Keuntungan atau manfaat yang akan didapatkan akan merangsang seseorang untuk melakukan tindakan yang menguntungkan bagi dirinya (Notoatmodjo, 2010). Disimpulkan bahwa respons positif memiliki peran yang penting untuk seseorang dalam mengambil suatu keputusan yang baik untuk kesehatannya. Apabila seseorang merasa manfaat yang dirasakan tidak terlalu besar maka mereka cenderung tidak melakukan tindakan yang baik dalam PHBS.

\section{KESIMPULAN}

Ada hubungan karakteristik (jenis kelamin dan tingkat kelas) dengan pelaksanaan Perilaku Hidup Bersih dan Sehat.

\section{SARAN}

Disarankan kepada Kepala Sekolah SMA Negeri 1 Pancur Batu membuat jadwal rutin tentang pelaksanaan PHBS sehingga derajat kesehatan anak sekolah lebih meningkat lagi yang merupakan aset negara untuk memperjuangkan negara Republik Indonesia mencapai status kesehatan yang baik.

Kepada Pihak Sekolah SMA Negeri 1 Pancur batu disarankan agar bekerjasama dengan Puskesmas Pancur Batu untuk membuat jadwal tentang pemberian pendidikan kesehatan sehingga pengetahuan anak sekolah lebih update tentang PHBS.

\section{UCAPAN TERIMA KASIH}

Penulis mengucapkan terimakasih kepada DRPM atas bantuan dana hibah penelitian, STIKes Santa Elisabeth Medan atas dukungan selama proses penelitian serta SMA Negeri 1 Pancur Batu atas izin dan kesediaannya memberikan data/ informasi.

\section{DAFTAR PUSTAKA}

Bachtiar (2015) Implementasi Program Gerakan Pungut Sampah (GPS) Dalam Meningkatkan Karakter Peduli Lingkungan (Studi Deskriptif Siswa Smp Di Kota Bandung). http://onesearch.id/Record/IOS2897. $\underline{17768 \text { ? widget }=1 \& \text { repository } \mathrm{id}=316}$ 6\#description (Diakses Mei 2017)

BPS, (2015). Badan Pusat Statistik. Jumlah Sekolah, Guru dan Murid Madrasah Aliyah (MA) di Bawah Kementerian Agama Menurut Provinsi

Glanz, K., Rimer, B. \& Viswanath, K. (2008). Health Behavior and Health Education: Theory, Research and Practice 4th edition. San Fra United States of America: Jossey-Bass.

Kemenkes RI, (2011), Pedoman Pembinaan Perilaku Hidup Bersih dan Sehat (PHBS), Jakarta

Lickona, T. (2012). Educating for Character: mendidik untuk membentuk karakter. Ahli bahasa: Juma Abdu Wamaungo. Jakarta: PT. Bumi Aksara

Maryunani (2013). Perilaku Hidup Bersih dan Sehat (PHBS) untuk mahasiswa kesehatan dan Petugas Kesehatan.Penerbit: Trans Info Media, Jakarta.

Notoadmodjo, (2007). Promosi Kesehatan dan Ilmu Perilaku. Jakarta: Penerbit Rineka Cipta

Notoatmodjo, S. (2010). Promosi Kesehatan dan Ilmu Perilaku. Jakarta: Rineka Cipta.

Notoatmodjo, S. (2012). Promosi Kesehatan di Sekolah. Jakarta: Penerbit Rineka Cipta

Notoatmodjo, S. (2014). Ilmu Perilaku Kesehatan. Jakarta: Rineka Cipta

Nurmalita (2016) Hubungan antara Jenis Kelamin, Tingkat Kelas, Pengetahuan, Dan Sikap Terhadap 
Perilaku Penggunaan Fasilitas MCK Di SDN 01 Kecubung Mulya, Lampung 2015, Program Studi Keperawatan STIK Sint Carolus, Jakarta

Riskesdas, (2013). Laporan Riset Kesehatan Dasar. Badan Penelitian dan Pengembangan Kesehatan Kementerian Kesehatan Republik

Sari, Widjanarko, Kusumawati, (2016) Faktor-Faktor Yang Berhubungan Dengan Perilaku Hidup Bersih Dan Sehat Sebagai Upaya Untuk Pencegahan Penyakit Diare Pada Siswa Di SDN Karangtowo Kecamatan Karangtengah Kabupaten Demak Jurnal Kesehatan Masyarakat (E-Journal) Volume 4, Nomor 3, Juli 2016 (Issn: 2356-3346)

Http://Ejournal-

S1.Undip.Ac.Id/Index.Php/Jkm

Sugianto (2017), Implementasi Perilaku Hidup Bersih Sehat Di Sekolah Dasar Se Kecamatan Jetis Yogyakarta, Skripsi, Fakutas Ilmu Keolahragaan Universitas Negeri Yogyakarta

Sugiyono (2013a). Statistika untuk Penelitian. Penerbit: Alfabeta, bandung

Sugiyono. (2013b). Metode Penelitian Kuantitatif Kualitatif dan $R$ \& $D$. Bandung: Alfabeta

Undang-Undang Republik Indonesia No 18 Tahun 2008 tentang Pengelolaan Sampah. Sekretariat Negara, Jakarta 